\title{
Plastic deformation and damage induced by fatigue in
}

\section{TWIP steels}

\author{
J. J. Roa ${ }^{1,2, *}$, G. Fargas ${ }^{1}$, J. Calvo ${ }^{1,3}$, E. Jiménez-Piqué ${ }^{1,2}$, A. Mateo ${ }^{1}$ \\ 1 Departament de Ciència dels Materials i Enginyeria Metal-lúrgica, Universitat \\ Politècnica de Catalunya. Avda. Diagonal 647, 08028 Barcelona (Spain) \\ ${ }^{2}$ CRnE, Campus Diagonal Sud, Edificio C', Universitat Politècnica de Catalunya, C/ \\ Pascual i Vila 15, 08028 Barcelona (Spain) \\ ${ }^{3}$ Fundació CTM Centre Tecnològic. Avda. Bases de Manresa 1, 08028 Manresa, \\ Barcelona (Spain) \\ *Corresponding author, e-mail: joan.josep.roa@upc.edu
}

\begin{abstract}
Twinning Induced Plasticity steels exhibit a high strain hardening rate which translates into a remarkable combination of ductility and strength. A thorough experimental approach was performed by advanced characterization techniques to study the deformation mechanisms developed under high cycle fatigue conditions. Results clearly lay out that the cumulative strain damage leads to strengthening but also induces microcracks at the intersection of twin boundaries which promote fracture.
\end{abstract}

Keywords: Twinning Induced Plasticity; High Cycle Fatigue; fracture mechanisms; deformation mechanisms. 


\section{Introduction}

The automotive industry is continuously making developments to decrease vehicle weight and thus polluting emissions, while improving crash performance by energy absorption of structural elements [1]. In this sense, recent developments of steel manufactures have led to the commercialization of multiphase TRIP (Transformation Induced Plasticity) and TWIP (Twinning Induced Plasticity) steels, in which phase transformation and twin formation, respectively, represent the reinforcing mechanisms. Stacking Fault Energy (SFE) is the main parameter that controls activation of the different deformation mechanisms, i.e., with a decreasing SFE the deformation mechanisms are sequentially: i) glide of dislocations in specific planes, which is the most common deformation pattern for metals; ii) formation of mechanical twins, also known as deformation twins; and iii) $\varepsilon$-martensite transformation (creation of a compact hexagonal phase). Mechanical $\varepsilon$-martensite transformation only occurs if the SFE is below $18 \mathrm{~mJ} \cdot \mathrm{mol}^{-1}$, whereas deformation twinning takes place if the SFE is in the range

of $12-35 \mathrm{~mJ} \cdot \mathrm{mol}^{-1}$ [2]. In TWIP steels, twin boundaries act as strong obstacles to dislocation motion, so twinning is considered a dynamic Hall-Petch mechanism [3]. As the formation of deformation twins involves the creation of new crystal orientations, twins progressively reduce the effective mean free path of dislocations and increase the flow stress, resulting in a high strain hardening $[4,5,6]$.

Fatigue limit is a key parameter for a reliable application of TWIP steels in automotive parts. One important limitation for the study of the fatigue behavior of those steels is the complexity of their microstructure, as it involves features of different length scales, from the micro- to the nanometric range [7]. Niendorf et al. [8] and Hamada et al. [9] studied the fatigue life for pre-deformed TWIP steel using flexural bending fatigue with 
zero mean stress. In both studies, they reported that after $2 \cdot 10^{6}$ cycles, the fatigue limit was around $400 \mathrm{MPa}$. Furthermore, TWIP steels deformation mechanisms as well as their fatigue behavior under low cycle fatigue conditions have been studied during the last years by several research groups [8,9,10,11,12,13]. Recently, Niendorf et al. [14] investigated the influence of pre-deformation and also the presence of notches on damage initiation of commercial high manganese steel under high cycle fatigue conditions. This investigation pointed out that the fatigue properties and notch sensitivity are altered drastically. Nevertheless, fatigue experiments performed under high cycle fatigue have received scarce attention and the corresponding deformation and fracture mechanisms activated are not straightforward. Although it is known that mechanical twinning is mainly activated [15] during fatigue cycles, it is required to shed some light trying to correlate the twinning density with the number of fatigue cycles as well as to better understand if the cracks activated during the fatigue experiments are a consequence of the mechanical twinning or an inherent defect present in the specimen. The goal of this work is to provide some evidence of the deformation and fracture mechanisms involved during fatigue tests of TWIP steels in the high cycle fatigue regime using advanced characterization techniques, such as atomic force microscopy (AFM), focused ion beam (FIB), field emission scanning electron microscopy (FESEM), electron backscatter diffraction (EBSD), transmission electron microscopy (TEM) and scanning-TEM (STEM).

\section{Experimental procedure}

\subsection{Sample preparation}


In this work, the studied material was $1.4 \mathrm{~mm}$ thick TWIP $17 \mathrm{Mn}$ steel sheet provided by POSCO (South Korea) in cold rolled plus annealed condition. Mean grain size for the investigated specimen was measured following the linear intercept method on micrographs taken with a FESEM, resulting in a grain size of $6.2 \pm 2.2 \mu \mathrm{m}$. The chemical composition and mechanical properties are shown in Tables $\mathbf{1}$ and 2, respectively. The surface of the specimens was initially grinded and subsequently polished using silicon carbide; and then with diamond suspension (30, 6 and $3 \mu \mathrm{m}$ ). Finally, in order to obtain a flat surface the specimen was subjected to a final surface polishing using a colloidal alumina suspension.

\subsection{Fatigue tests}

Regarding cyclic loading, testing was aimed to determine the fatigue limit, defined as the fatigue strength corresponding to a life of $1.2 \cdot 10^{6}$ cycles. It was done following the staircase or up-and-down method [16]. Specimens were machined following the ASTM E466-96 Standard [17]. Tests were carried out employing a resonant testing machine at working frequencies of about $150 \mathrm{~Hz}$ and a load ratio $\left(\mathrm{R}=\sigma_{\min } / \sigma_{\max }\right)$ of 0.1 . The maximum stress to initiate the staircase procedure was taken as $550 \mathrm{MPa}$, value corresponding to around $40 \%$ of the ultimate tensile strength. Several replicas were taken for atomic force microscopy (AFM) observation in the same region of interest (40 $\mathrm{x} 40 \mu \mathrm{m}^{2}$ ) to observe the surface damage evolution at two different stages of the fatigue

life (see Fig. 1). In order to do it, in one of the test was stopped after $5 \cdot 10^{5}$ cycles and then continued up to $1.2 \cdot 10^{6}$ cycles.

\subsection{Surface observation}


Surface analyses were performed by field emission scanning electron microscopy (FESEM) at $20 \mathrm{kV}$ and AFM working in tapping mode. All the AFM images were processed with WSxM software [18].

\subsection{Sub-surface damage characterization}

Focused ion beam/FESEM (FIB/FESEM) techniques were used to analyze the fracture initiation and to elucidate the deformation mechanisms below the surface. A thin platinum layer was deposited on the sample prior to FIB with the aim of reducing ionbeam damage. $\mathrm{A} \mathrm{Ga}^{+}$ion source was used to mill the surface at a voltage of $30 \mathrm{kV}$. The final polishing of the cross-sections was performed at a current of $500 \mathrm{pA}$.

\subsection{Microstructural characterization}

Electron Backscattered Diffraction (EBSD) analyses in the region of interest were carried out on a FESEM operating at $20 \mathrm{kV}$. The orientation imaging microscopy (OIM) software developed by TSL was used to index Kikuchi diffraction patterns [19]. The intensity of Kikuchi lines is greatly dependant on the local crystallographic orientation. The diffraction response of grains oriented with a surface normal to the basal direction was sufficient for indexing with beam current in the order of $1 \mathrm{nA}$. EBSD measurements were performed in two different zones: inside the maximum stress field and difference fracture regions at $50 \mathrm{~nm}$ of scanning steps in order to have better resolution; an acceleration voltage of $20 \mathrm{kV}$ and beam currents up to $9 \mathrm{nA}$ were used. 
In order to better understand the deformation mechanisms and determine the twinning planes activated during the fatigue tests, small regions were characterized using TEM and STEM. For TEM observations, a TEM-lamella was taken from the region of interest by FIB using decreasing currents down to a final polishing stage at $5 \mathrm{kV}$ and 10 pA. The lamella observation was done in a STEM coupled with a FIB microscope. Furthermore, a TEM using an acceleration voltage of $120 \mathrm{kV}$ was employed for microstructural observations and to obtain several electron diffraction patterns of the region of interest in order to compare the possible twinning planes with the data given by EBSD analyses.

\section{Results and discussion}

\subsection{Fatigue limit}

The fatigue limit $\left(\sigma_{f}\right)$ [20] of the studied TWIP steel was experimentally determined following the staircase method. The stress vs. the number of specimen in sequence is represented in Fig. 2. Using the equations proposed by Grove et al. [21], the corresponding fatigue stress limit is $579 \pm 50 \mathrm{MPa}$ for $1.2 \cdot 10^{6}$ cycles. As it can be appreciated in the figure, deformation strengthening of the commercial TWIP steel is produced due to the accumulation of the mechanical twins during high cycle fatigue experiments. During the fatigue tests, plenty of different deformation and damage events were activated, which will be discussed in the oncoming sections.

\subsection{Microstructure study in the plastic deformation region}


The TWIP steel studied here presents a distribution of titanium nitrides (TiN) with a size of a few micrometers, Fig. 3a to Fig. 3c are AFM images (error signal mode) taken in the same region (close to two inclusions) but at different number of fatigue cycles, i.e., $0,5 \cdot 10^{5}$ and $1.2 \cdot 10^{6}$, respectively. It is straightforward to mention that the nitrogen in the presence of $\mathrm{Al}$ and $\mathrm{Ti}$, both $\mathrm{AlN}$ [22] and TiN are likely to precipitated due to that are formed at very high temperatures, during solidification. The different inclusions observed by means of AFM presents a square-like morphology, which were identified as TiN [23]. Nearby those nitrides, the stress concentration should be different due to different expansion coefficients and crystallographic structure between inclusions and matrix. However, no additional deformation mechanisms were observed close to these TiN particles. Moreover, it is important to highlight that after $5 \cdot 10^{5}$ cycles, several mechanical twins were formed, indicating that the activation of twins can take place at macroscopic load levels corresponding to the elastic zone in the tensile stress-strain curve.

Images on Fig. 3 do not show the generation of $\varepsilon$-martensite due to the stress field induced during the fatigue tests. According to De Cooman et al. [20], the main responsible to limit the nucleation of the $\varepsilon$-martensite phase is the $\mathrm{Al}$ content $(1.9 \%)$ in the TWIP steel. Furthermore, as the strain accumulation increases with the number of cycles, the volume fraction of twins increases steadily, continuously dividing grains into smaller units [24]. More specifically, the dominant deformation mode in TWIP steels is dislocation glide, and the deformation-induced twins gradually reduce the effective glide distance of dislocations which results in the Dynamical Hall-Petch effect [3]. One twin system is activated at the early stages of plastic deformation, followed by the nucleation of secondary twin systems between the boundaries of the primary set of twins, leading to a ladder-like structure [25]. Moreover, twins grow on a macroscopic 
scale with ongoing deformation, which is mainly attributed to the stacking of microscopic twins, as reported by Allain et al. [25]. In order to nucleate the different types of twins, a critical shear stress level needs to be attained, for instance by stress localization brought about by dislocation pile-ups. In this case, local stresses increase and allow the formation of new twins.

Thus, a dynamic Hall-Petch effect can be considered, since the effective grain size is continuously being decreased. Fig. 3d is an AFM topography image which shows a profile of several twins and the same region in $3 \mathrm{D}$ view, for a sample tested up to $5 \cdot 10^{5}$ cycles. Two different grains and two different twinning directions, which correspond to the direction of emergence of the (111) plane onto the surface, can be observed. A close examination of the profile of the twinning region reveals a non-periodic structure composed by small steps of several nanometers $(30-60 \mathrm{~nm})$ in height, equally spaced by $1 \mu \mathrm{m}$. Moreover, the three-dimensional representation of the topographic AFM image of the twinned region shows a large step at the left side edge of the image, which can be attributed to a grain boundary between two austenite grains. In this 3D image, the difference in the orientations of the twins belonging to different grains is also evident. This grain orientation dependence of twinning explains that the density of twins and the space between them inside each grain are different, see Fig. 3 (i.e. in the AFM image at $1.2 \cdot 10^{6}$ cycles, see white dot square). It is also worth mentioning that after fatigue deformation, it becomes easier to identify the grain boundaries. This effect can be attributed to the emergence of the different twins to the surface, which is the responsible of the differences in stress distribution between the center of the grain and its boundary, being higher close to the grain boundaries.

The FESEM image on Fig. 4 exhibits a detail of the grain boundary where the maximum stress localization, brought about by dislocation pile-ups, is concentrated 
during the fatigue test. Also, several micro-cracks with a serrated shape are observed near some grain boundaries close to the fracture zone (see white arrows in Fig. $\mathbf{4 b}$ ). This fracture mechanism can be attributed to the high stress concentration produced by the emergence of deformation twins at grain boundaries and/or by twin-twin intersection. The serrated crack morphology results when the interface is halted just below the free surface and its stress field is relieved by matrix slip, on the protruding side of the tilted surface $[26,27,28,29]$. These results indicate that micro-cracks undergo stress relaxation in some crystallographic orientations, in agreement with Low [30], who reported the same effect and crack shape for 3\% Si-Fe.

Twin mobility during cyclic loading occurs earlier than the formation of twins markings at the surface. Nevertheless, a twin system is supposed to be activated when associated twin traces are observed at the surface. To identify the twin system activated in austenite grains, EBSD measurements were performed. Fig. 5 shows the microstructure through the EBSD analysis of several grains in the region of interest. In order to make the description easier, the grains have been numbered. The EBSD map of Fig. 5a reveals the presence of straight dark lines within some grains. These lines illustrate the deformation twins, which appear within the initially equiaxial austenite grains as thin parallel bands dividing the grains. Grain 3 presents an estrange feature appearing at a grain boundary (see white dotted line); a boundary is present in the middle of this grain however no crystal rotation can be observed by EBSD data.

Fig. 5b illustrates the EBSD mapping of the deformed surface showing the normal direction (ND) orientations. All the different grains present in the region of interest have been numbered and their ND orientations are in the ND inverse pole figure (IPF). Twins are clearly observed at the resolution of the EBSD analysis after fatigue tests in Fig. $\mathbf{5 b}$. Moreover, such twins are mostly present in $<111>$ grains parallel to the tensile axis. 
This is in accordance with previous observations of various TWIP steels subjected to tensile tests $[31,32,33,34,35]$ but not under fatigue. Besides, as reported by Lee [36], the Schmid factor for mechanical twinning in $<111>$ oriented grains is larger than for dislocation slip in $<001>$.

As previously reported in the literature $[37,38,39,40]$, the twins retain an average thickness of $100-400 \mathrm{~nm}$. Moreover, the white arrow in the image quality map (Fig. 5a) for grain number 9 presents a boundary. No crystallographic rotation can be observed in the inverse pole figure image (Fig. 5b). Thus, this boundary can be related to a low angle twin boundary. The intra-granular misorientations resulting from the deformation were analysed by measuring the cumulative misorientation profiles along the thick black lines in several grains (see Fig. 5c). Such intra-granular misorientations for grains 3, 6 and 11 can be associated to the formation of dislocations, because the cumulated misorientation is lower than $10^{\circ}$. This effect has been previously observed by Verbeken et al. [41], Jorge-Badiola et al. [42] and Barbier et al. [43]. Consequently, the dislocation activity always is viewed as a precursor to the twinning process. This consideration is in correct agreement with Karaman et al. [44] and Ding et al. [45]. Therefore, over a distance of $15 \mu \mathrm{m}$ (grains 1 and 7), the cumulated misorientation reaches a value higher than $60^{\circ}$. Several fundamental mechanisms for mechanical twinning in fcc materials are proposed in the literature [46], probably due to the heterogeneous character of the observations. Furthermore, as it can be observed from the profiles, the twin thickness is different from one grain to another. Thus, the grain size and crystallographic orientation play a significant role in the thickness of the deformation twins. This agrees with the data reported by Soulami et al. [46]. In literature, there are several twinning mechanisms proposed for this steel grade: the study of Venales [47] referred to pole mechanisms; Cohen and Weertman $[48,49]$ 
considered the dissociation of a perfect dislocation into a sessile Frank partial screw dislocation and a mobile Schokley partial dislocation; based on the presence of an extrinsic stacking fault developed by Mahajan and Chin [50]; and the work of Karaman et al. [51], specific for Hadfield steels.

EBSD analysis was carried out in order to explain the mechanisms involved during the twin boundary motion in order to create a new twin boundary under a stress field, Fig. 5. This event was observed concretely in grain number 6, where the IQ (Fig. 5a) and the IPF (Fig. 5b) show a boundary in the middle of the grain and a crystallographic rotation, respectively. Then, this boundary in the middle of the grain can be attributed to a deformation twin boundary. As showed in the schema of Fig. 6, deformation twins present a pile-up of partial dislocations in the twin boundary. Hence, when the strain accumulated due to cyclic loading becomes higher than the critical stress for deformation twins in TWIP steels, the partial dislocations present in the deformation twin boundary will glide and translate this boundary a certain distance (see Fig. 6b). The dislocation displacement corresponds to the movement of the twin boundary and thus propagation of the twin area. This movement of the twin boundary corresponds to the new zone, swept by the twinning dislocations, which are still mobile at room temperature. This consideration is in correct agreement with Albou et al. [52], who suggested the creation of orientation gradients within the matrix at the onset of plasticity due to dislocation glide activity, leasing a progressive rotation of the $\{111\}$ plane of the matrix, which becomes the twinning plane once the critical resolved shear stress of twin nucleation is reached. Furthermore, Wu et al. [53] observed that the first mechanisms activated under nano-compression of pillars was the movement of partial dislocations, which is the main cause to create the twinning mechanism. 
Characterization of the deformation and damage mechanisms at the end of the fatigue test ( $N=1.2 \cdot 10^{6}$ cycles) was performed by cross-sectional analysis, perpendicular to the surface and across the grain boundary, using FIB and FESEM, as shown in Fig. 7. One section was milled in a region where several grains were involved in the deformation process. Fig. 7a shows a general view of the trench of interest obtained by FIB. Furthermore, the deformation twins and their direction can be easily observed, as well as the grain boundary, in the middle of the image. The white dot line plotted in Fig. 7b shows that in the vicinity of the grain boundary the surface is not flat. This phenomenon is attributed to the high concentration of stresses in the interface between two different crystallographic grains due to the emergence and intersection of deformed twin boundaries. Fig. 7c illustrates a bimodal grain size distribution, with fine grains close to the surface and coarse ones after the first 50-100 nm of depth. Several authors assumed this feature to be related to the surface damage created during the sample preparation (mainly in the grinding process) and not with an amorphization effect induced by the $\mathrm{Ga}^{+}$ions as well as due to the final polishing step [54,55]. The fine grains are generated during the preparation of the surface by grinding and polishing before the fatigue test. These new grain boundaries close to the surface are responsible to the blocking of some dislocation movements, thus leading to a slight increase in the SFE to produce the activation and emergence of dislocations into the surface. Furthermore, the white arrow shows a twin of several micrometers passing through one grain and blocked close to the grain boundary. In order to reveal the microstructure in the trench of interest, the zone of study was exposed to the ion beam during several seconds and afterwards it was observed by FESEM, see Fig. 7d. This image corresponds to a region close to the one observed in Fig. 7c but at a lower magnification. In this zone, primary and secondary twins were detected. Primary twins 
go from grain boundary to grain boundary, whereas secondary twins extend from twin boundary to twin boundary.

The STEM micrograph perpendicular to the surface and across two different grains corresponding to Fig. 7c is presented in Fig. 8. At the top of this image, the Pt layer can be observed. Furthermore, this image shows the emergence of second order twins into the surface (see black arrows). The high stress concentration generated during the growing of first order twins produced an internal crack. This result is in correct agreement with Fig. 4, where several cracks were visualized in the grain boundary.

The TEM micrograph and the diffraction pattern corresponding to $1^{\text {st }}$ and $2^{\text {nd }}$ order twins close to a grain boundary is presented in Fig. 9. Fig. 9a shows a microstructure with a high density of dislocations and several clear bands. The selected area diffraction pattern (SADP) reveals a splitting spot, mainly related with the crystallographic orientation yielding a zone axis of [011]. Furthermore, the small satellites indicate the band to be a twin or another artefact surrounding the region of study.

\subsection{Microstructural study in the fracture region}

Kim et al. [56] suggested that the fracture mechanisms in TWIP steels are related to martensitic transformation in the presence of residual stresses. This consideration can be accepted for TWIP steels containing less than $1 \%$ of Al. However, this is not the case of the material studied here, which presents an $\mathrm{Al}$ content close to $2 \%$. Thus, this supposition is not in good agreement with the observation performed by FESEM (Fig. 10a) and AFM (error signal mode, Fig. 10b), around $50 \mu \mathrm{m}$ from the fracture zone. According to these images, the damage generated during the tensile fatigue tests can be 
explained by the high strain accumulated which promotes intensive twinning and thus some micro-cracks with a serrated geometry nucleate at grain boundaries.

White arrows in Fig. 10a indicate a cavity created before the fracture. This cavity and/or micro-cracks play an important role because they decrease the high stress field generated during the emergence and accumulation on the surface of deformation twins at grain boundaries. A typical aspect of an intergranular crack is given in Fig. 10a. Moreover, it was observed that many areas on this sample exhibited numerous intergranular cracks localized near grain boundaries (see Fig. 4a). Furthermore, due to the intensive twinning creation, a pull-out effect of TiN particles can also be appreciated (see dash white square). Fig. 10b exhibits an AFM image at $50 \mu \mathrm{m}$ from the fracture region, showing the intensive twinning due to the high accumulated strain just before the fracture process.

Fig. 11a shows the FESEM image at $70^{\circ}$ of the fracture region of study after high cycle fatigue tests. The black dash square presents the zone of observation by EBSD. Fig. 11b presents the corresponding quality map. Twins are clearly visible as thin reoriented lamella, which shows massive deformation twins. This phenomenon indicates that the strain hardening and the superior ductility of TWIP steels are mainly due to the interaction of twins and dislocations. Moreover, Fig. 11c illustrates a typical orientation map of the specimen fractured. By means of such orientation mapping, it is possible to investigate the crystallographic relationships precisely. Therefore, it is worth emphasizing that standard EBSD analyses cannot provide such accurate microstructural data, since the high density of defects deteriorate the indexing level, leading to nonindexed pixels because the fracture zone is out of the indexation plane.

\section{Conclusions}


As a result of this study on the plastic deformation and damage induced by high cycle fatigue tests in TWIP steels, the following conclusions were made:

(i) The dislocation density is the factor determining the prevalence of the nucleation and growing process of mechanical twins during fatigue testing. This mechanism produces a twin motion due to the partial dislocation movement along the whole grain which is similar to macroscopic shearing, but it takes place on a distinct plane and needs a different shear force to be activated.

(ii) The TWIP steel grains with a crystallographic orientation close to (111) plane present a high amount of deformation twins.

(iii) Serrated microcracks nucleated during fatigue tests are related to a high accumulated strain which induces intensive twinning.

(iv) Several cavities near to the fracture region were appreciated by surface characterization techniques, corresponding to pull-out events of TiN inclusions heterogeneously distributed in the austenite matrix.

(v) The fracture event in TWIP steels can be related to two different factors: propagation of serrated microcracks nucleated in the grain boundaries and, less important, the pull-out effect of TiN inclusions.

\section{Acknowledgements}

The authors greatly acknowledge Dr. T. Trifonov from “Centre d'Investigació en Nanoengeniería, CRNE-UPC" for his help in FIB technique and I. López Insa from the “Laboratori de Microscòpia Electrònica del CMEM-UPC" for his contribution to the 
FE-SEM and EBSD image analysis. Moreover, we would like to thank POSCO (South Korea) for supplying the material of this study. Furthermore, the presented work was carried out within the scope of MAT09-14461 and MAT12-34602 projects, supported by the Spanish Ministery of Economy. We are grateful to "Direcció General de Recerca del Comissionat per a Universitats i Recerca de la Generalitat de Catalunya” for recognizing CIEFMA and PROCOMAME as consolidated Research Groups (2014SGR130). One of the authors (J. J. Roa) would like to thank the Juan de la Cierva programme (grant number: JCI-2012-14454) for its financial support.

\section{Figure captions}

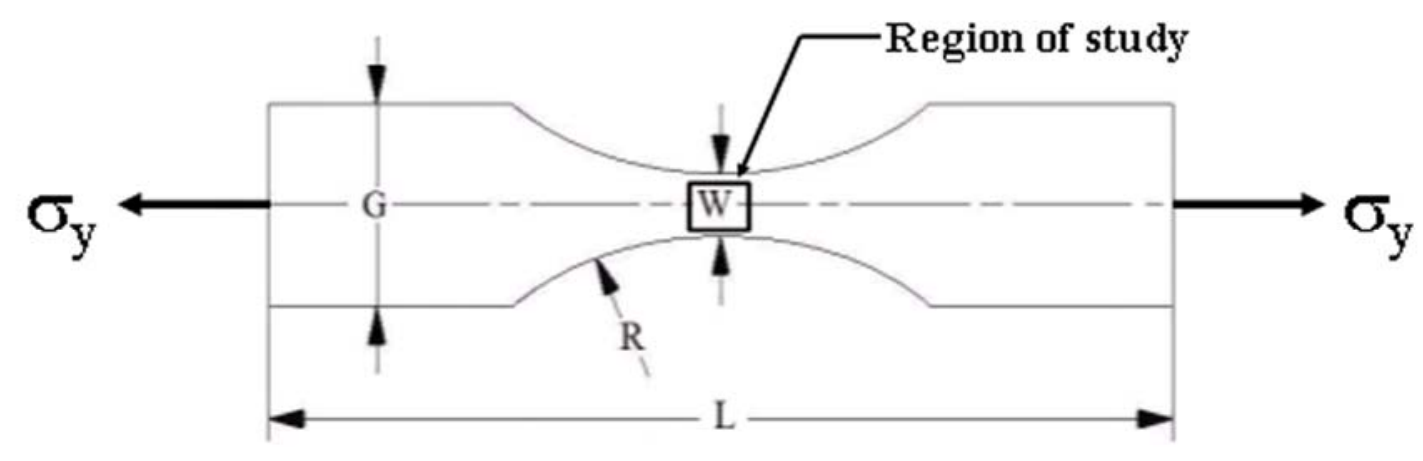

Fig. 1. Scheme of the studied region where the deformation mechanisms were analyzed after high cycle fatigue tests. 


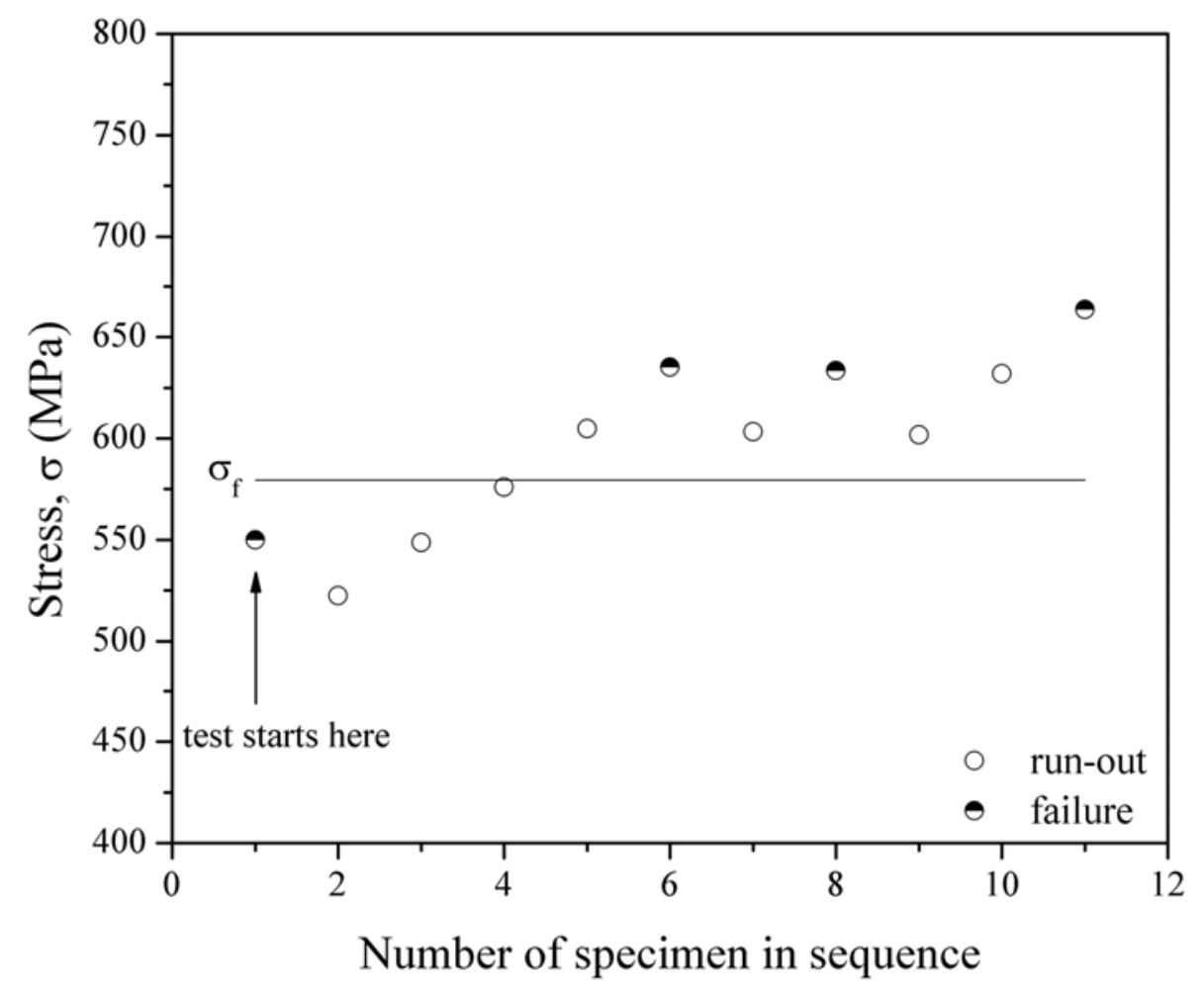

Fig. 2. Up-and-down fatigue tests used to determine mean fatigue limit ( $\left.\sigma_{f}\right)$ for the TWIP steels. 


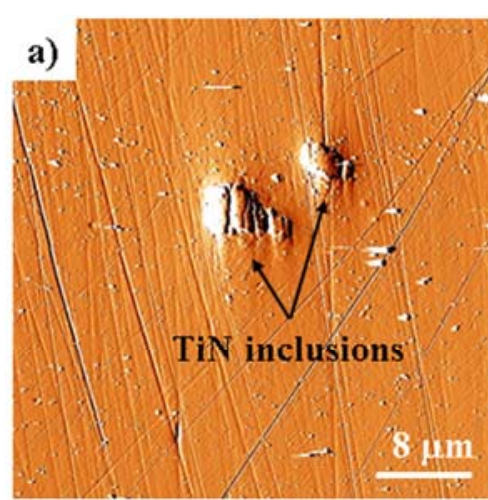

$N=0$ cycles

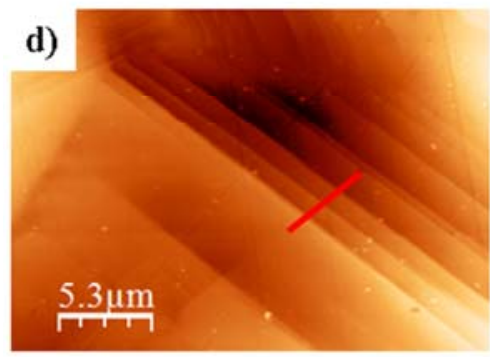

$N=5.0 \cdot 10^{5}$ cycles

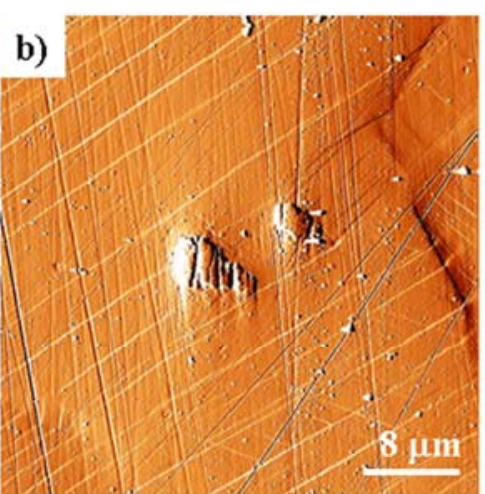

$N=\mathbf{5 . 0} \cdot 10^{5}$ cycles

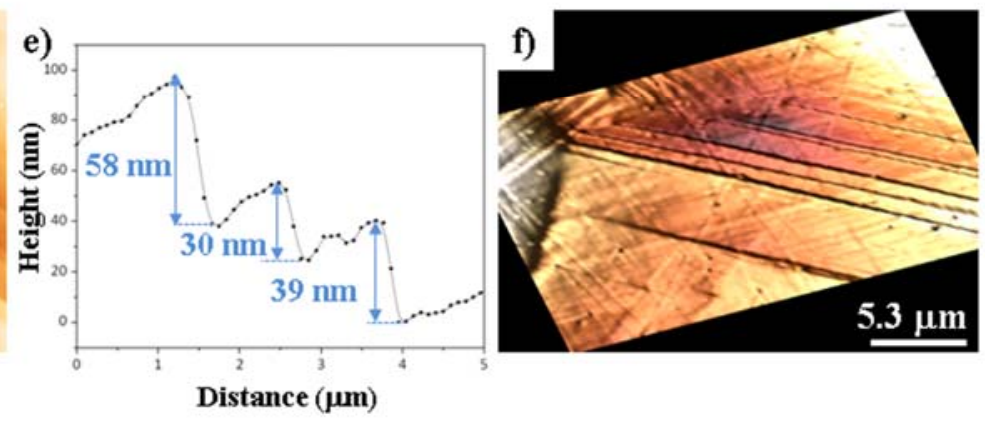

Fig. 3. AFM error signal mode images of the studied region after different $N$ cycles of fatigue. (a) Initial state, $\mathrm{N}=0$ cycles, (b) at $N=5.0 \cdot 10^{5}$ cycles, and (c) at $N=1.2 \cdot 10^{6}$ cycles. The same TiN particles can be observed in all the AFM images. (d) Detail of the surface topography showing several twins after $N=5.0 \cdot 10^{5}$ cycles. (e) Cross section profile of several twins. (f) A $3 \mathrm{D}$ representation of the topography image in (d).
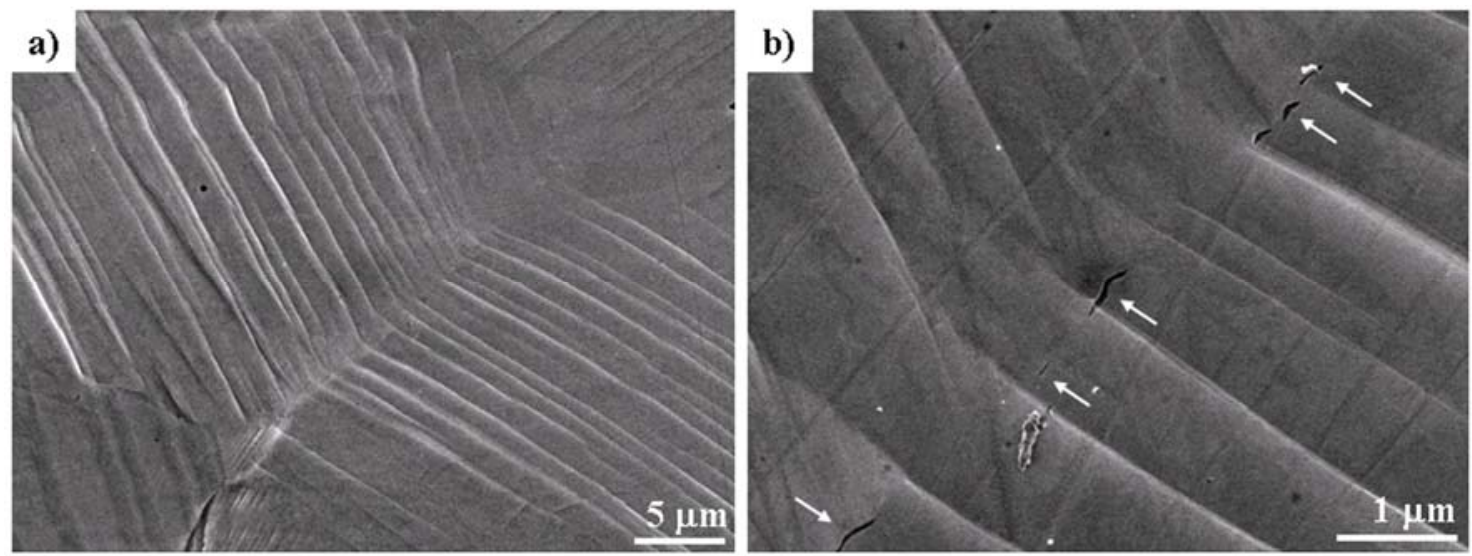

Fig. 4. FESEM images at $N=1.2 \cdot 10^{6}$ cycles. (a) Twin-twin interaction at the grain boundary, far from the fracture zone. (b) Magnification of the grain boundary showing several microcracks with a serrated shape. 
a)

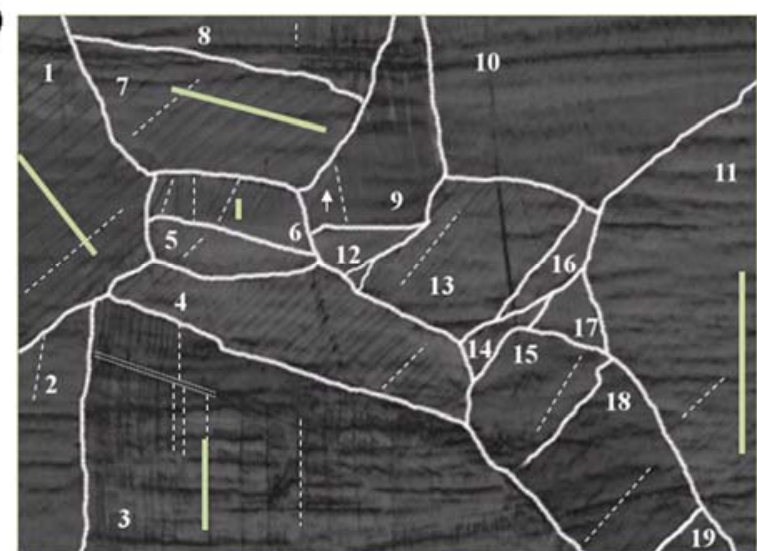

b)

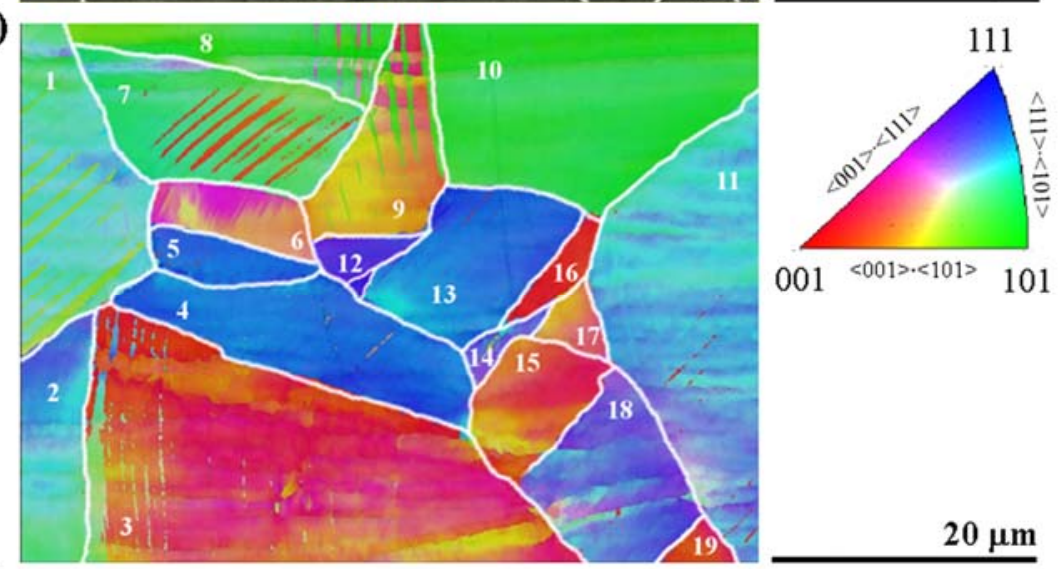

c)
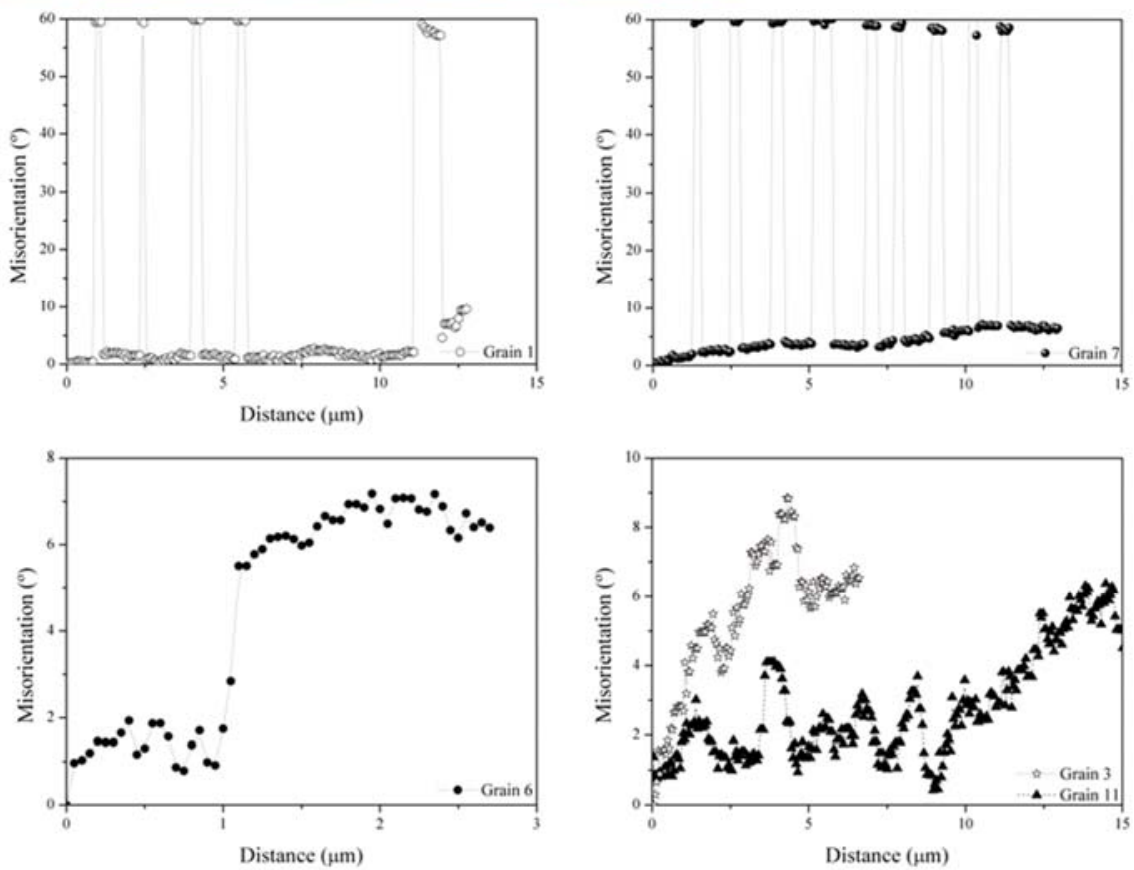

Fig. 5. (a) Electron backscatter diffraction (EBSD) map (band contrast) showing the mechanical twins appearing within the grains. The white dash lines show the twin direction inside each grain, and (b) EBSD orientation imaging analysis of TWIP steel showing the normal direction (ND) orientations of the $50 \times 50 \mu \mathrm{m}^{2}$ investigated area after tensile deformation. (c) Misorientation profiles along the black line in twin (grain 1 and 7) and no-twin (grains 3, 6 and 11) grains of figure (a) and (b). Step size employed was $50 \mathrm{~nm}$. The grains have been numbered for easier identification. 

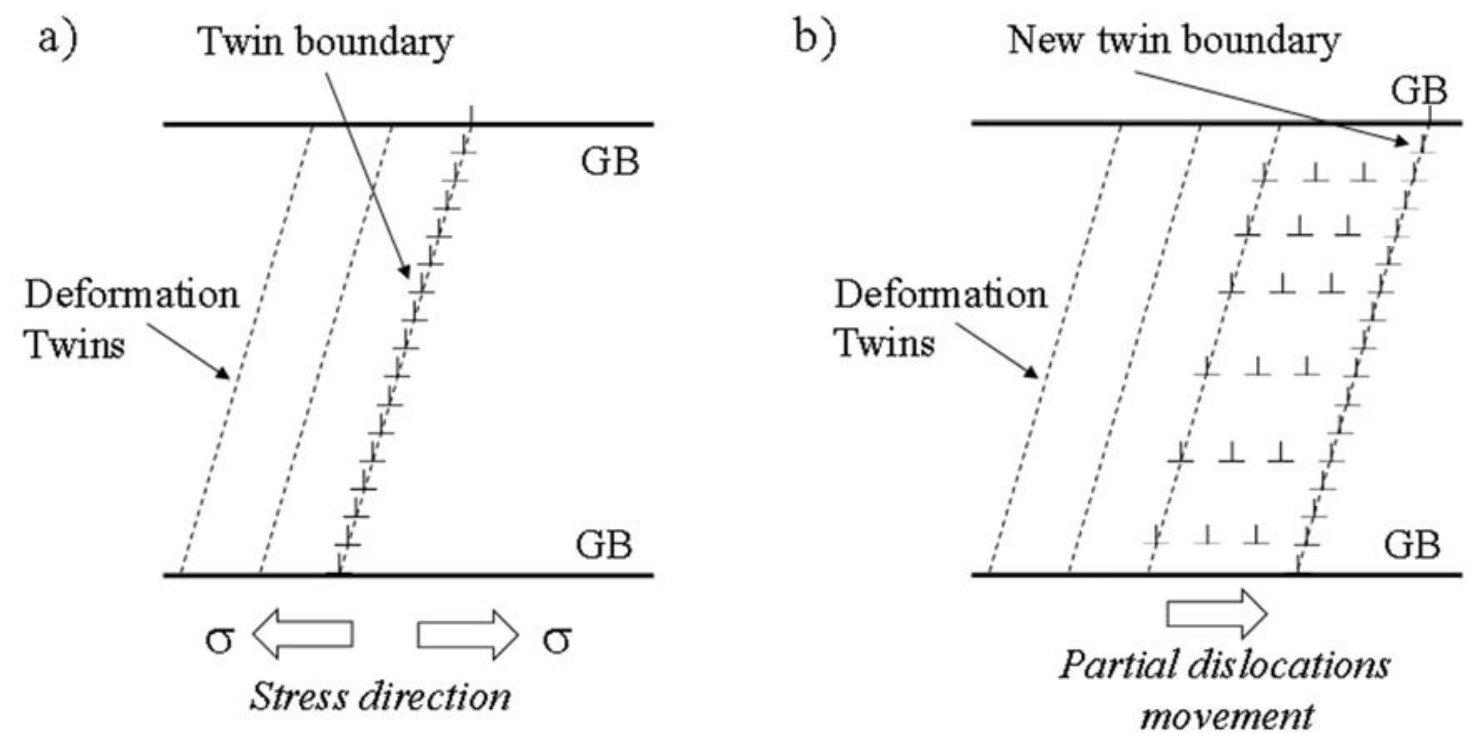

Fig. 6. Scheme of the deformation twin motion under a stress field. Where GB denotes the grain boundary.
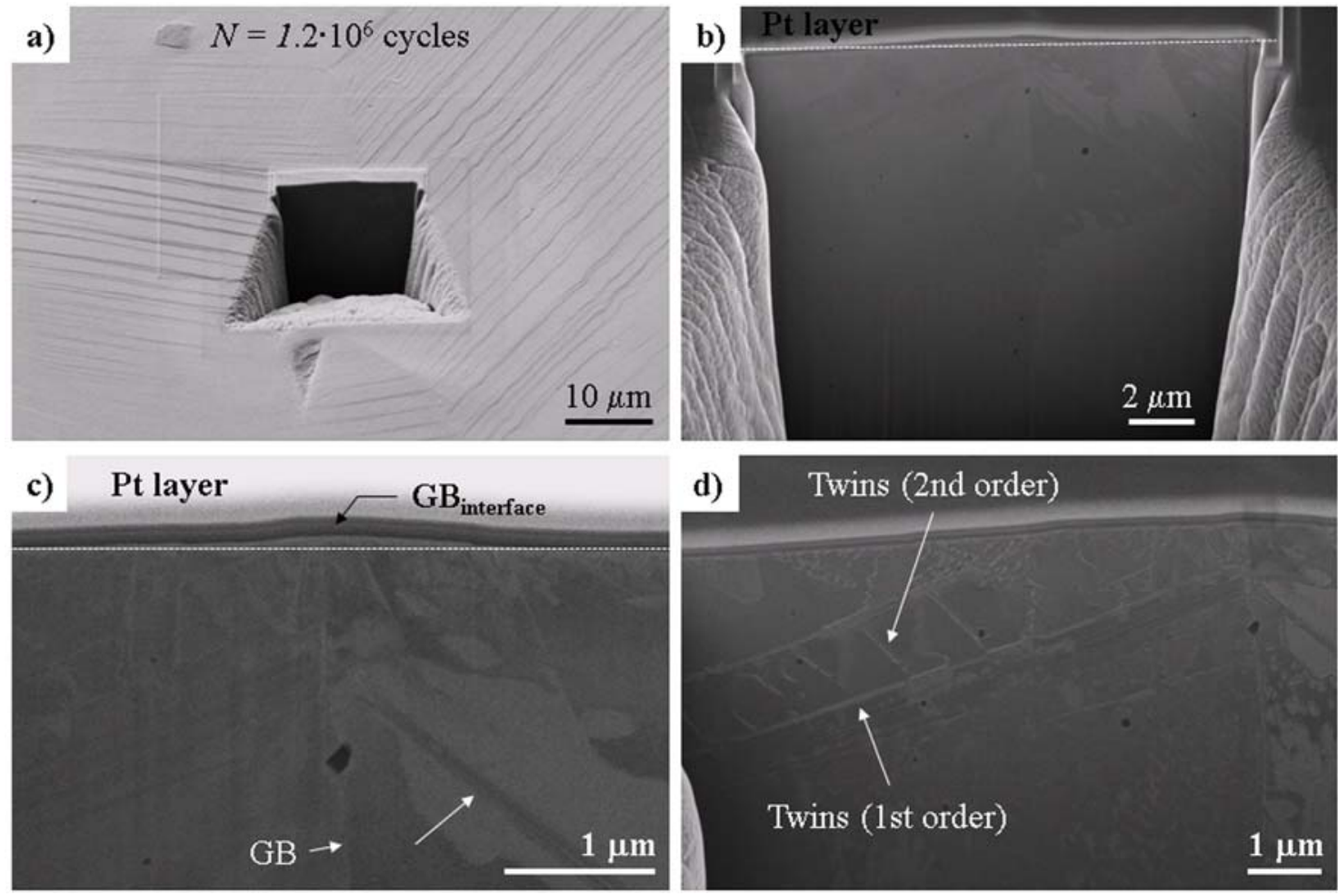

Fig. 7. Characterization of the twin-twin interaction at grain boundaries using the FIB/FESEM after $1.2 \cdot 10^{6}$ fatigue cycles: (a) general view of the region of interest, (b) cross-sectioning of the twin-twin interaction at the grain boundary showing the internal microstructure, (c) magnification of the centre of the image (b) showing the interaction of the grain boundary with two different twins, and (d) magnification in the left part of the image (b) after several seconds of exposure to ion beam to reveal the microstructure. This image shows primary and secondary twins. 


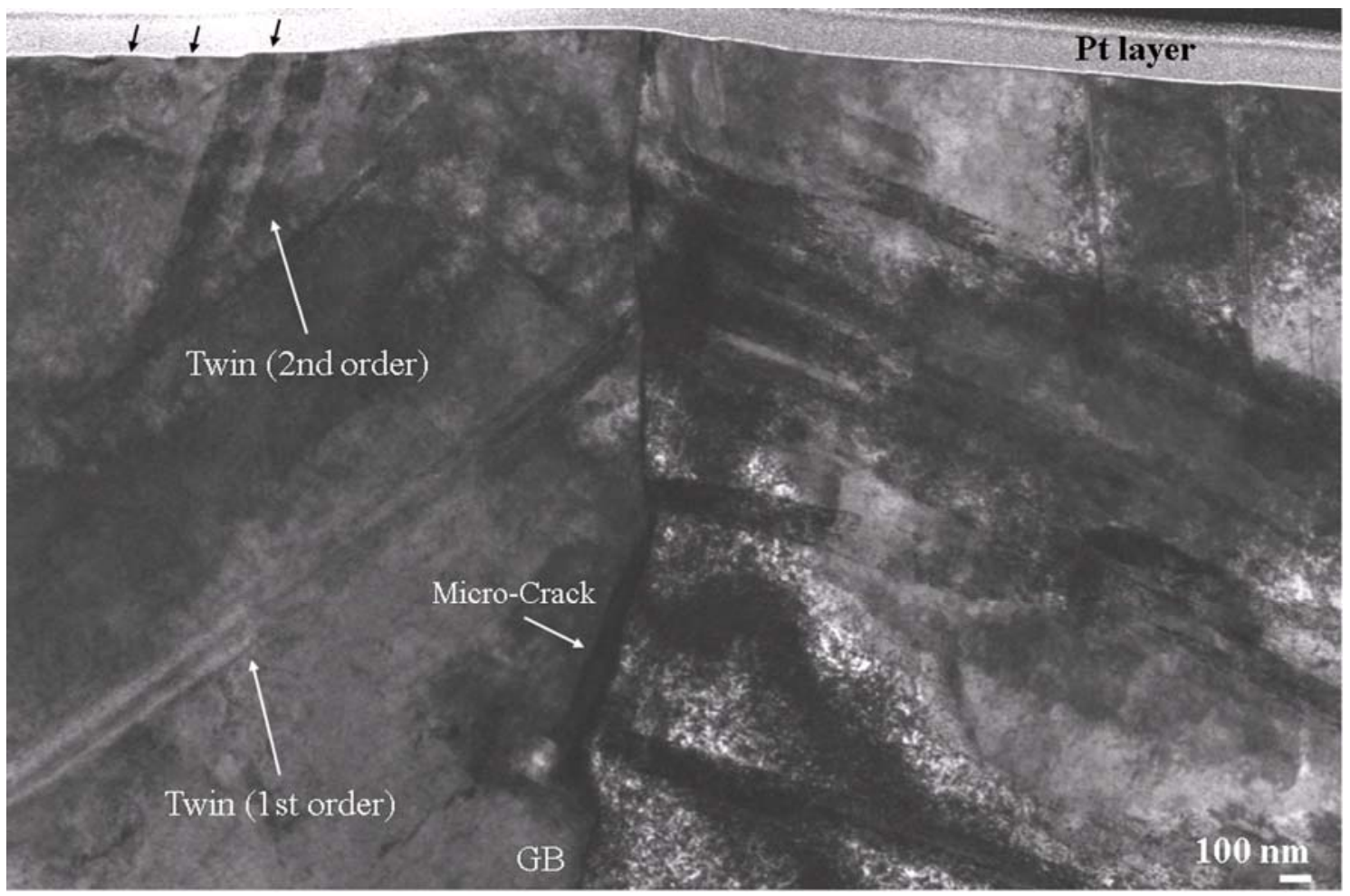

Fig. 8. STEM micrographs (dark field mode) of TWIP steels in the region of study after high cycle fatigue $\left(N=1.2 \cdot 10^{6}\right.$ cycles $)$.

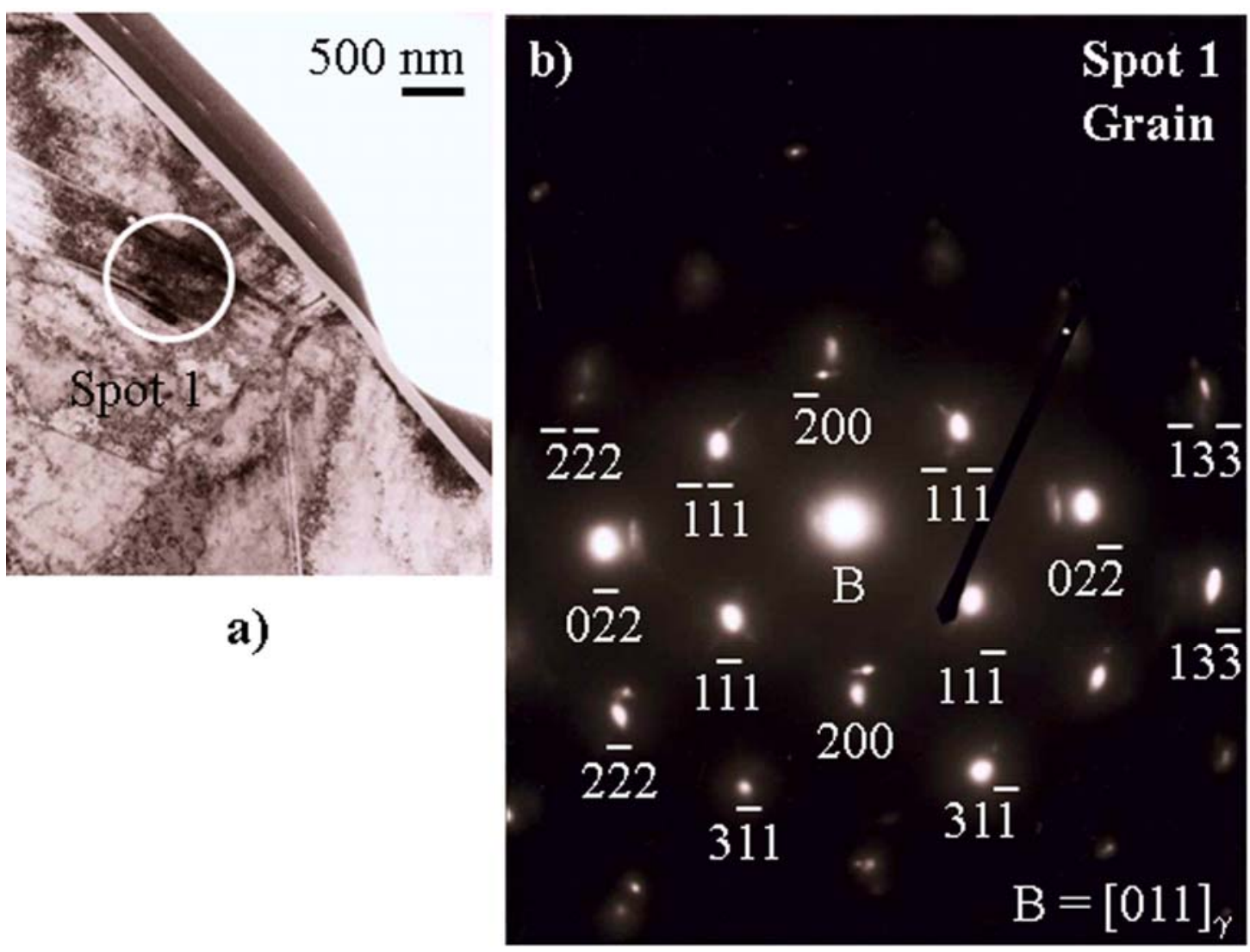

Fig. 9. a) TEM micrographs of the studied zone and electron diffraction pattern in: b) spot 1 . 

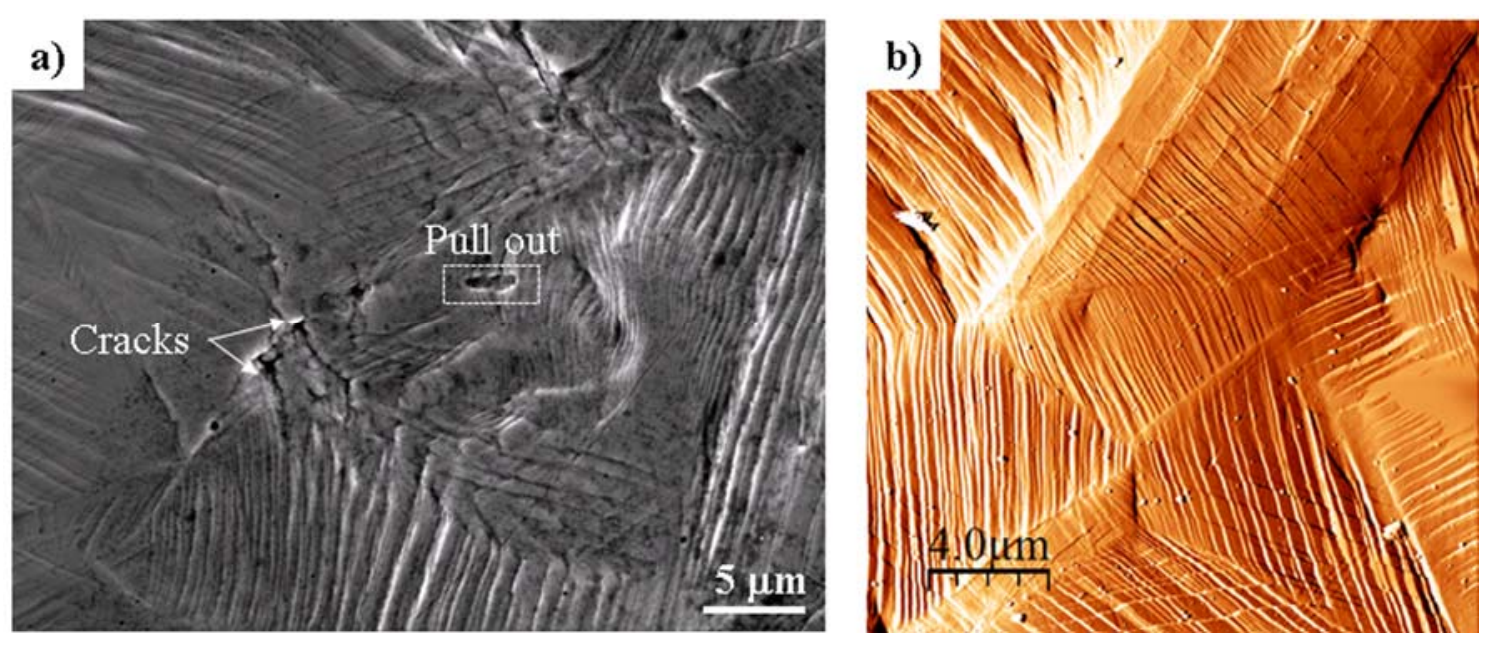

Fig. 10. (a) FESEM image at $N=1 \cdot 2 \cdot 10^{6}$ cycles nearby the fracture zone, showing the intensive twinning creating high amount of micro-cracks and cavities. (b) AFM error signal mode image $\left(20 \times 20 \mu \mathrm{m}^{2}\right)$ nearby the fracture region.
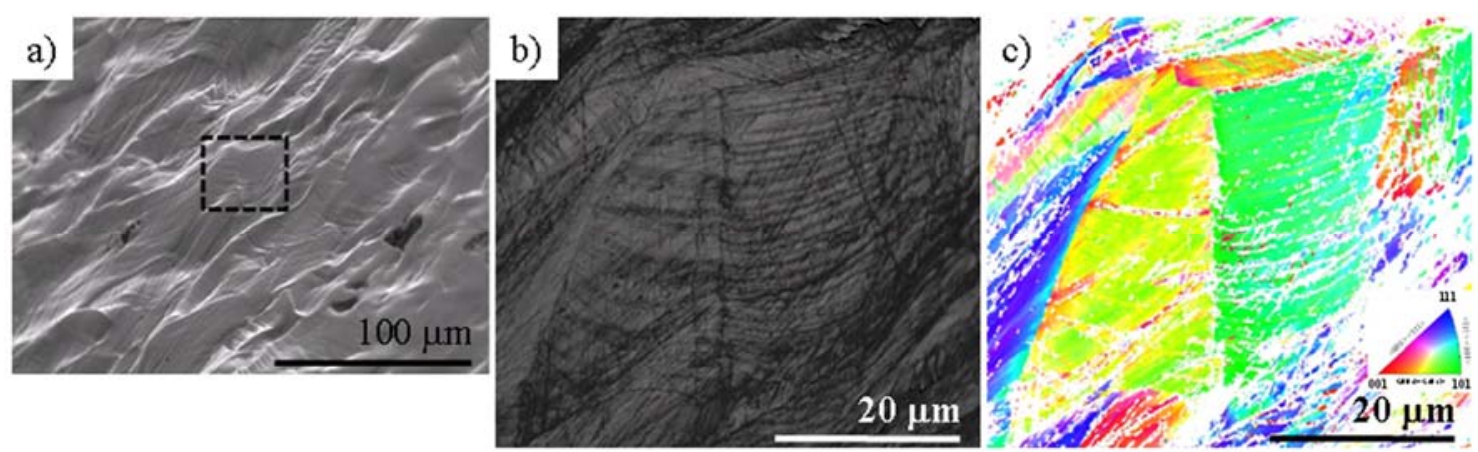

Fig. 11. Poor diffraction quality map obtained on the fracture region by means of EBSD analysis showing the typical features of surface deformation and crack initiation site on TWIP steels (after $1.2 \cdot 10^{6}$ cycles).

\section{Table captions}

Table 1. Chemical composition of the studied TWIP steel (wt.\%)

\begin{tabular}{|l|l|l|l|l|l|l|l|l|l|}
\hline $\mathrm{C}$ & $\mathrm{Si}$ & $\mathrm{Mn}$ & $\mathrm{S}$ & $\mathrm{Mo}$ & $\mathrm{Al}$ & $\mathrm{Nb}$ & $\mathrm{Ti}$ & $\mathrm{V}$ & $\mathrm{Fe}$ \\
\hline 0.722 & 0.071 & 16.76 & 0.015 & 0.343 & 1.922 & 0.021 & 0.096 & 0.037 & Bal. \\
\hline
\end{tabular}

* The $\mathrm{N}$ content was not specifically determined, although it is considered that there is always some $\mathrm{N}$ (ranged between 0.010 to $0.025 \mathrm{wt} \%$ ), which could remain in the steel from the casting stage.

Table 2. Mechanical properties for the commercial TWIP steel

\begin{tabular}{|l|l|l|}
\hline Ultimate tensile stress, $\sigma_{\text {uts }}(\mathbf{M P a})$ & Yield stress, $\sigma_{\text {ys }}(\mathbf{M P a})$ & $\mathbf{H V}_{\mathbf{1 0}}$ \\
\hline 1500 & 441 & 232 \\
\hline
\end{tabular}




\section{References}

[1] N. Ohkubo, K. Miyakusu, Y. Uematsu, H. Kimura, ISIJ Int. 34 (1994) 764-772.

[2] S. Allain, J. P. Chateau, O. Bouaziz, S. Migot, N. Guelton, Mat. Sci. Eng. A 387389 (2004) 158-162.

[3] I. Karaman, A. Sehitoglu, A. J. Beaudoin, Y. I. Chumlayakov, H. J. Maier, C. N. Tomé, Acta Mater. 48 (2000) 2031-2047.

[4] O. Grässel, L. Kruger, G. Frommeyer, L. Meyer, Int. J. Plast. 16 (2000) 1391-1409.

[5] G. Frommeyer, U. Brux, P. Neuman, ISIJ Int. 43 (2003) 438-446.

[6] A. Prakash, T. Hochrainer, E. Reisacher, H. Riedel, Steel Res. Int. 79 (2008) 645652.

[7] I. Gutierrez-Urrutia, D. Raabe, Acta Mater. 59 (2011) 6449-6462.

[8] T. Niendorf, C. Lotze, D. Canadinc, A. Frehn, H. J. Mater, Mat. Sci. Eng. A. 499 (2009) 518-524.

[9] A. S. Hamada, L. P. Karjalainen, J. Puustinen, Mat. Sci. Eng. A. 517 (2009)68-77.

[10] Y. X. Wu, D. Tang, H. T. Jiang, Z. L. Mi, Y. Xue, H. P. Wu, J. Iron Steel Res. 21 (2004) 352-358.

[11] I. Nikulin, T. Sawaguchi, K. Tsuzaki, Mat. Sci. Eng. A 587 (2013) 192-200.

[12] P. C. Guo, L. H. Qian, J. Y. Meng, F. C. Zhang, L. F. Li, Mat. Sci. Eng. A 584 (2013) 133-142.

[13] A. Glage, C. Weigelt, J. Rathel, H. Biermann, Adv. Eng. Mat. 15 (2013) 550-557.

[14] T. Niendorf, P. Klimala, H. J. Maier, A. Frehn, Mat. Sci. Forum 706-709 (2012) 2205-2210. 
[15] A. Hamada, D. Porter, J. Puustinen, L. P. Karjalainen, Mat. Sci. Forum 762 (2013) 411-417.

[16] J. A. Collins. Failure of materials in mechanical design. New York, USA: John Wiley \& Sons Inc; 1981. pp. 369-374.

[17] ASTM E466-96. Standard Practice for Conducting force Controlled Constant Amplitude Axial Fatigue Tests of Metallic Materials, 2002.

[18] I. Horcas, R. Fernández, J. M. Gómez-Rodríguez, J. Colchero, J. Gómez-Herrero, A. M. Barom, Rev. Sci. Instrum, 78 (2007) 013705/1-013705/8.

[19] S. I. Wright, B. L. Adams, Metall. Trans. 23A (1992) 759-760.

[20] N. A. Fleck, K. J. Kand, F. Ashby, Acta Metall. Mater. 42 (1994) 365-381.

[21] D. Grove, F. Campean, Qual. Reliab. Engng. Int. 24 (2008) 485-497.

[22] S. E. Kang, A. Tuling, J. R. Banerjee, W. D. Gunawardana, B. Mintz, Mater. Sci. Tech. 27 (2011) 95-100.

[23] I-J. Park, S. Y. Jo, M. Kang, S.-M. Lee, Y.-K. Lee, Corrosion Sci. 89 (2014) 38-45.

[24] S. Allain, J. -P. Chateau, O. Bouaziz, Mater. Sci. Eng. A 387-389 (2004) 143-147.

[25] S. Allain, J. -P. Chateau, D. Dahmoun, O. Bouaziz, Mater. Sci. Eng. A 387-389 (2004) 272-276.

[26] D. Hull, Deformation Twinning (edited by R. E. Redd-Hill, J. P. Hirth and H. C. Rogers), Gordon and Breach, New York, 1963, pp. p.121.

[27] J. W. Christian, S. Mahajan, Prog. Mat. Sci. 39 (1995) 1-157.

[28] E. El-Danal, S. R. Kalidindi, R. D. Doherty, Int. J. Plasticity 17 (2001)1245-1365.

[29] M. A. Meyers, O. Vohringer, V. A. Lubarda, Acta Mater. 49 (2001) 4025-4039.

[30] B. L. Averbach, D. K. Felbeck, G. T. Hahn, D. A. Thomas. Fracure. Editors John Wiley and Sons, Inc., New York, 1959. 
[31] D. Barbier, N. Grey, S. Allain, S. Bozzolo, M. Humbert, Mater. Sci. Eng. A 500 (2009) 196-206.

[32] P. Yang, Q. Xie, L. Meng, H. Ding, Z. Tang, Scripta Mater. 55 (2006) 629-631.

[33] J. Jimenez, G. Frommeyer, Mater. Character., 61 (2010) 221-226.

[34] I. Gutierrez-Urrutia, S. Zaefferer, D. Raabe, Mater. Sci. Eng. A 527 (2010) 35523560.

[35] S. Dancette, L. Delannay, K. Renard, M. A. Melchior, P. J. Jacques, Acta Mater. 60 (2012) 2135-2145.

[36] Y.-K. Lee, Scripta Mater. 66 (2012) 1002-1006.

[37] K. Renard, H. Idrissi, D. Schryvers, P. J. Jacques, Scripta Mater. 66 (2012) 966971.

[38] H. Idrissi, K. Renard, L. Ryelandt, D. Schryvers, P. J. Jacques, Acta Mater. 58 (2010) 2464-2476.

[39] H. Idrissi, K. Renard, D. Schryvers, P. J. Jacques, Scripta Mater. 63 (2010) 961964.

[40] A. Albou, M. Galceran, K. Renard, S. Godet, P. J. Jacques, Scripta Mater. 68 (2013) 400-403.

[41] K. Verbeken, L. Kestens, Mater. Sci. Forum 408 (2002) 559-564.

[42] D. Jorge-Badiola, A. Iza-Mendia, I. Gutiérrez, J. Microsc. 228 (2007) 373-383.

[43] D. Barbier, N. Gey, S. Allain, N. Bossolo, M. Humbert, Mat. Sci. Eng. A 500 (2009) 196-206.

[44] I. Karaman, H. Sehitoglu, K. Gall, Y. I. Chumlyakov, Acta Mater. 48 (2000) 13451359. 
[45] H. Ding, H. Ding, D. Song, Z. Tang, P. Yang, Mater. Sci. Eng. A 528 (2011) 868873.

[46] A. Soulami, K. S. Choi, Y. F. Shen, W. N. Liu, X. Sun, M. A. Khaleel, Mat. Sci. Eng. A. 528 (2011) 1402-1408.

[47] J. A. Venables. Philos. Mag. A 30 (1974) 1165-1169.

[48] J. B. Cohen, J. Weertman. Acta Metall. 11 (1963) 996-998.

[49] J. B. Cohen, J. Weertman. Acta Metall. 11 (1963) 1368-1369.

[50] S. Mahajan, G. Y. Chin. Acta Metall. 21 (1973) 1353-1363.

[51] I. Karaman, H. Sehitoglu, K. Gall, Y. I. Chumlyakov, H. J. Maier. Acta Mater. 48 (2000) 1345-1359.

[52] A. Albou, M. Galceran, K. Renard, S. Godet, P. J. Jacques, Scripta Mater. 68 (2013) 400-403.

[53] S. Z. Wu, H. W. Yen, M. X. Huang, A. H. W. Ngan, Scripta Mater. 67 (2012) 641644.

[54] J. J. Roa, G. Fargas, E. Jiménez-Piqué, A. Mateo, Mat. Sci. Eng. A 597 (2014) 232-236.

[55] J. A. Muñoz, E. Jiménez-Piqué, J. Reyes, M. Anglada, Acta Mater. 59 (2011) 6670-6683.

[56] Y. Kim, N. Kang, Y. Park, G. Kim, S. Kim, K. Cho, J. Korean Inst. Met. \& Mater. 46 (2008) 780-788. 